\title{
Pedagogical Diagnostics of Professional and Cultural Competences of University Students
}

\author{
Elena N. Prokofieva ${ }^{1}$, Irina I. Leyfa ${ }^{2}$, Gulnara R. Ibraeva ${ }^{3}$, Linar G. Akhmetov ${ }^{4}$, Ilya N. Maksimov ${ }^{4}$, Ludmila V. \\ Marfina $^{5}$, Marina A. Demyanenko ${ }^{2} \&$ Yuliya L. Kamasheva ${ }^{6}$ \\ ${ }^{1}$ The Institute of Pedagogic and Psychology of Professional Education of Russian Academy of Education, Kazan, \\ Russia \\ ${ }^{2}$ Amur State University, Blagovechensk, Russia \\ ${ }^{3}$ Kazan State Power Engineering University, Kazan, Russia \\ ${ }^{4}$ Kazan (Volga region) Federal University, Kazan, Russia \\ ${ }^{5}$ Kazan State University of Architecture and Engineering, Kazan, Russia \\ ${ }^{6}$ Institute of Economics, Management and Law, Kazan, Russia \\ Correspondence: Elena N. Prokofieva, The Institute of Pedagogic and Psychology of Professional Education of \\ Russian Academy of Education, Isaeva Street 12, Kazan, 420039, Russia. E-mail: frau.levina2010@yandex.ru
}

Received: January 19, 2014 Accepted: February 22, 2015 Online Published: March 30, 2015

doi:10.5539/res.v7n5p161 URL: http://dx.doi.org/10.5539/res.v7n5p161

\begin{abstract}
The purpose of this article is aimed at studying the problem of increasing the formation of students' diagnostic skills in the course of training at a university. The presented article demonstrates a technique for diagnosing the level of professional and cultural competences formation on the basis of students' effectiveness in quasi professional environment. The basis of the presented work is formed by the ideas of the competence approach, their qualitative tools, expert assessment of the educational activities of university students. The article describes a method of assessing competences, criteriaë and levels of formation and methods of their estimation, allowing a diagnostics of educational activities. This article is intended for teachers, researchers, educational institutions heads who deal with the diagnostics of educational activities.
\end{abstract}

Keywords: higher education, professional competences, cultural competences, a professional profile

\section{Introduction}

\subsection{Background}

The main goal of modern higher education is to prepare a qualified specialist (a bachelor, a master, a postgraduate student) who is ready to a professional activity and growth, having social and professional mobility, ability to adapt in changing external conditions (Prokofieva, 2012; Frolov, 2004; Telegina et al., 2015). A competence characterizes a specifics of professional activity and quality of modern university graduate training. A significant element of a competence is an experience that is the integration of single actions, methods and problems solving techniques, achieved by a man, into a single unit. Expression of professional competences requires constant updating and increase of professional knowledge, acquisition of new information for the successful solution of professional tasks by university students. For the first time the education raises the question concerning the continuity of the competences development by stages of learning, it requires accounting for the specific competences in each direction of professional training (Azarov, 2008; Ephremova, 2010; Kalimullin, 2014;Gutman et al., 2014; Ivanenko et al., 2015).

Competences are the result of higher education and determined by its ability and willingness to fulfill professional and social activities in the selected discipline.

\subsection{Status of a Problem}

In the current environment of a competence paradigm it requires a change in a system of knowledge control of university students, working out such an evaluation system that would adequately reflect the process of professional and cultural competence formation. There are substantially modifying the forms of training, there is 
a shift towards the use of active and problem methods where students can demonstrate their abilities to the full extent, that is the problem of evaluation of learning activities characteristics and personal students' qualities comes forward (Chirkina, 2015). Accordingly, there is a need for such an evaluation system, which would be able to integrate all the methods, evaluation forms and have a cumulative character throughout the training period.

The analysis of scientific literature shows that the problem of professional competences formation attracts the attention of scientists (Baydenko, 2004; Zimnyaya, 2006; Muhametzyanova, 2010; Novikov, 2006, etc.). The research in the field of standardization and education quality evaluation on the basis of the competence approach is considered in researchers' works (Zeer, 2005; Levina, 2012; Hrapal, 2010; Selezneva, 2002; Hutorskoy, 2003, etc.).

However, employers' qualification requirements for a modern specialist are still at the stage of formation, while the learning process has been built on the formation of professional and cultural competences, established by educational standards. In addition, there are no developments of a universal evaluation system of university students' professional and cultural competences at the present moment.

\subsection{The Research Hypothesis}

The evaluation system of university students' professional and cultural competences will be effective if it is developed a technique that uses qualitative, qualimetric and expert evaluation, which form the graduates' professional profile basing on an accumulative system.

\section{Materials and Methods}

\subsection{A Competence as a Result of Higher Education}

Competences, describing the learning results, are a set of knowledge, skills, abilities and personal qualities that a graduate can demonstrate after getting a bachelor's or a master's degree. A professional competence is an integral characteristic that determines the ability to solve professional problems and typical professional tasks arising in real situations of professional activity, involving knowledge, professional and life experiences, values and inclinations (Ibragimov, 2011; Potashnik, 2002; Levina et al., 2015).

The general meaning of the professional competence is considered from the point of view of a specialist's competitiveness in the labor market, responding to employer's requests, willingness to perform certain actions qualitatively.

The competence specific character, as a result of education, is that in comparison with other results of education it is: an integrated result of learning, it appears and exists in the form of activity, rather than information about it; it is connected with a significant number of activity objects, it can be increased in conjunction with other competences, forming a professional competence; the competence, as an action, appears not automatically, but consciously and repeatedly appearing, forms the professional experience.

The competence approach is more focused on achieving a quality of training that meets economic and social needs of the public, creating a balance between the demand of the labor market and the interests and professional fulfillment of the personality. It is important to determine the structure of professional and cultural competences, methods of formation and methods of their evaluation in order to do this. We propose to use a quail metric approach providing a measurement numerically or in provisional figures; a combination of research methods aimed at obtaining diverse information about the object, tracking the dynamics of its indicators changes and analysis of possible deviations will provide a transition from qualitative, one-side description of the phenomena to the objective, precise methods of verification and generalization of students learning results.

\subsection{The Algorithm of University Students' Professional and Cultural Competences Diagnostics}

The authors have developed the algorithm of university students' professional and cultural competences diagnostics, including:

Stage 1. Definition of professional and cultural competences and their structure in the direction of learning;

Stage 2. Definitionof methods of professional and cultural competences formation for each discipline;

Stage 3. Forming the base of control and evaluation tools of professional and cultural competences diagnostics for each discipline;

Stage 4. Formation of the university student's professional profile including an integrated evaluation of all professional and cultural competences.

Stage 5. Analysis of the diagnostics results of professional and cultural competences from the perspective of 
students, teachers, university administration, employers.

This algorithm implements the structuring function (registration of standard requirements, an employer, university administration) to the objectives and the content of training, the control function (the development of control evaluation tools, their information security and continuous monitoring) and the management function (based on the adjustment of educational material acquisition process basing on the results of the competences diagnostics).

\section{Results}

\subsection{Definition of the Professional and Cultural Competences of the University Graduates in the Direction of Training}

The measure of a competence - practical application of knowledge and skills in a time limit, supplemented by personal qualities - motivation, discipline, organization, commitment, etc.

At the initial stage of the diagnostic tools development it is important to analyze FSES (Federal State Educational Standards) and identify the types of activity and a set of professional and cultural competences, required for their acquisition, for each direction of training.

Structural components of professional competences for each profile are identified on the basis of analysis of the professional activity subject, structural components of the culture, of qualitative criteria of a personality (Isaev, 2008; Meshcheriakova, 2013; Sharshov, 2004).

We offer as structural components of the professional competences: cognitive (completeness and generality of professional knowledge), activity (development and formation of professional abilities, skills), communicative (teamwork, management decisions), axiological (moral-value positions) components which can be formed on the three evaluation levels - low (reproductive activity), average (independent productive activity), high (independent creative activity).

\subsection{Determination of Methods of Professional and Cultural Competences Formation in the University Vocational Training}

The second stage of technique development of diagnostic tools is to determine the content of training for each discipline and a set of pedagogical forms, methods and techniques that contribute to the professional and cultural competences formation. The graduate's competences should allow him/her to work successfully in the chosen professional field, acquire socio-personal and cultural qualities, promote social mobility and stability in the labor market. The leading forms of modern graduates training are active learning methods that recreate not only objective, but also the social content of future professional activity. During this training the student must perform the exact actions in the quasiprofesisonal environment, similar to those that will have a definite place in his/her career. Particularly successful use of active methods such as pedagogical techniques, from our point of view, may be after work experience internship where students receive certain knowledge about enterprises condition, areas of the region, students have the opportunity to work with the normative documentation, to acquire workplaces.

Certainly such points as the level of development of competences in the traditional teaching (lectures, practice, laboratory works, seminars), personal development of the student, external factors and others contribute to making this assessment. However, empirical observations of students during this training show an increase of interest and professional orientation, acquisition of professional terms, ways of communication and interaction within active learning methods.

For each type of lessons, developed within the curriculum and the discipline program, the formed set of pedagogical techniques is necessary to determine the competences evaluation method.

\subsection{The Basis of Control and Evaluation Tools for the Professional and Cultural Competences Diagnostics}

Competences themselves have a cognitive (knowledge and understanding of professionally relevant information), activity (how-to-act knowledge) and personal (how-to-be knowledge) basis. Bachelors' achievements are quantitative and qualitative indicators of acquisition of a simulation professional work and they reflect the process of development and movement toward the goal of professional training - a high level of competences. Consequently, to the results of the professional and cultural competences formation should be attributed the acquired competences, value attitudes, formed personality qualities.

Cognitive and partly activity base of competences, formed within lectures, practical and laboratory classes, can be checked with the help of traditional evaluation tools: oral and written surveys, control and self tests, a system of entry, progress and final tests with regard to the objectives of diagnostic. Tests are constructed with account 
for the taxonomy of goals using problem and situational tasks.

Within active learning methods (business games, project methods, etc.) we recommend the use of expert evaluation of professional and cultural competences as a way of diagnosing students' actions (appearances of a competence).

Each competence, exhibited by the student, is associated with an action or an event that is fixed by an expert, in addition, it is also estimated the final result of a task (a goal of an active method -a developed project or an achieved level, a solved problem). Accordingly, every student's action should be recorded in a special card of competences, which takes into account, in addition to the demonstrated level (low, medium, high) also a personal contribution, that is, whether the competence is manifested in one's own or in a group activity.

To determine the level of professional and cultural competences within active learning methods it is necessary on the average 5 precedents who allow making a diagnostics. The overall result of theoretical and practical discipline acquisition is stored in the specially organized automated database, allowing an accomplishment of education gaps for their timely correction (both for students and teachers).

\subsection{Formation of the University Student's Professional Profile}

We propose to build a student's professional profile for each direction of training based on the established standards of professional and cultural competences. The perfect condition is an achievement of a high level (an independent creative activity) on all components of the selected competences to consider as the professional profile, for example, if in the consideration of the direction and training profile the professional (PC1-PC18) and cultural competences $(\mathrm{CC} 1-\mathrm{CC} 11)$ are formed, so the professional profile can be represented as a $100 \%$ satisfaction (Figure 1).

According to the results of each discipline acquisition, after each test the database is filled. A cumulative evaluation of a student is an additive evaluation of all his/her actions within a single discipline. Each discipline has a certain share (a percentage of participation) in the formation of various professional and cultural competences. The overall result on all disciplines within the training is accumulating in a personal student's base, where at the end of the term the student's correspondence to the profession profile is determined (Figure 2).

At the final stage of the proposed diagnostic technique of professional and cultural competences it is necessary to analyze the effectiveness of training on the level of each student, a student group, a studied discipline during the selected time period (a week of training, a term, an academic year, a whole period of studies) for objective analysis and possible adjustment of training process.

Experimental implementation of the proposed diagnostic tools into the teaching practice of Kazan National Research Technological University named after A. N. Tupolev (for the administering sub-department (Industrial and Environmental Safety) and the general education sub-department (Computing Mathematics) has demonstrated its effectiveness which is determined by:

-Updating the content of disciplines in accordance with the requirements of the FSES (Federal State Educational Standards) and employers in modern conditions, that enhances the professional direction of education;

-Selection of effective pedagogical techniques with the use of active and interactive teaching methods for the formation of selected professional competences;

-Improvement of evaluation tools of a discipline;

-Automation of the collecting, storing and analyzing information system;

-Transparency of the educational process for the university administration;

-Increase of motivation and progressin studies of students, participating in the experiment, an average increase of $28 \%$. 


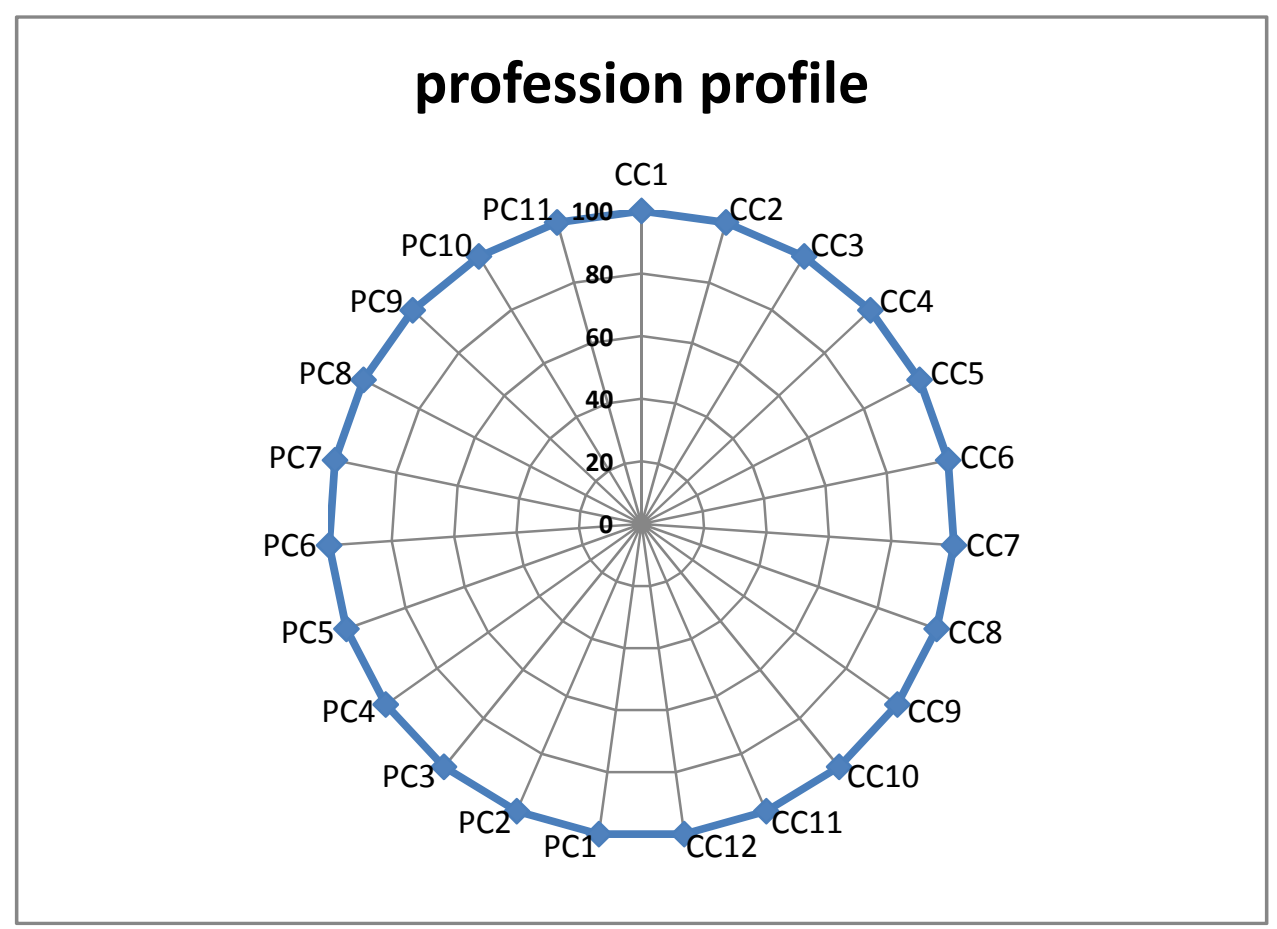

Figure 1. The example of the profession profile in the direction and profile of training

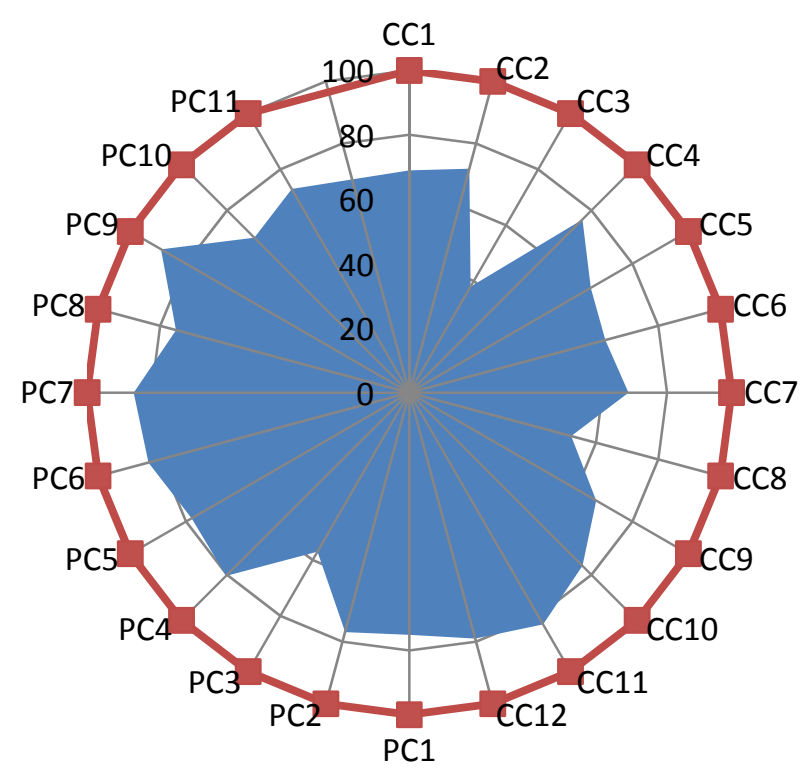

the profession profile for university students

$\rightarrow$ - profession profile

Figure 2. The correspondence of the level of students' professional and cultural competences to the profession profile for university students

\subsection{The Analysis of Diagnostic Results of Professional and Cultural Competences}

The use of this evaluating system allows you to:

-Get an evaluation of achievement of competences individually by each student in each discipline, theme and type of lessons;

-Identify the individual qualities of each student, their professional competency and personal qualities, such as a 
group work, behavior and ability to a teamwork, leadership qualities and etc.;

-Diagnose gaps in students' assimilation of knowledge and skills during the traditional training and competences within active learning methods and implement their timely correction;

-Receive full information about the professional skills of the students by the university administration and potential employers.

\section{Discussions}

Modern conditions of educational activity suggest that the result will be not the amount of knowledge received by a student, but his/her ability and willingness to work in the chosen professional field, the competitiveness of the labor market.

The determination of the graduates' competences diagnostic technique, the necessary criteria and characteristics with the use of information automated tools enables the teacher to carry out monitoring of his/her own activities and student's activities identifying the necessary aspects for adjustment.

For students within the diagnostics of professional competences the process of modeling their own professional activities is taking place, as well as the strategy for professional training in the university depending on the profile of future activities is developing. During the diagnostics it is forming a system of values which characterizes the integrity of a person, persistence in achieving his/her goals, an attitude to oneself, to knowledge, to one's future profession.

\section{Conclusions}

The accession of Russia to the Bologna process and changing the model of the higher school involve a focus shift from educational content to its results, which must be transparent for a graduate, teachers, university administration and employers. The employer must be aware of the bachelors' or masters' success in education, their ability to apply professional knowledge, skills in practice for identification of the workplace and a type of professional activities. The proposed methodic is a universal diagnostic tool, it has the ability to adapt to any direction of training in the higher education system, it is easy to use and has the ability to embed into the information system of the university.

\section{Acknowledgments}

The authors thank all participants of this study for their kind cooperation.

\section{References}

Azarov, R. N. (2008). Designing competence-oriented and competitive basic educational programs of HPE implementing GEF VPO. Guidelines (p. 81). Ufa Research Center challenges the quality of training.

Baydenko, V. I. (2004). Competence in vocational training. Journal of Higher education in Russia, 11, 4.

Chirkina, S. E. (2015) Features of formation of future educational psychologists' professional identity during their retraining. Review of European Studies, 7(1), 161-165.

Ephremova, N. F. (2010). Approaches to the evaluation of competencies in higher education (p. 216). Research Center problem the quality of training.

Frolov, O. V. (2004). Competence model as a basis for assessing the quality of specialist training. Higher education today, $8,87$.

Gutman, Y. Y., Masalimova, A. R., Shaidullina, A. R., Nizamieva, A. M., \& Myhamadieva, A. H. (2014). Foreign Language discipline integrative potential in the students' research competence forming. American Journal of Applied Sciences, 11(7), 1099-1103. http://dx.doi.org/10.3844/ajassp.2014.1099.1103

Hrapal, L. R. (2010). Diagnostic tools to identify the level's modernization ethno-cultural identity of the future specialist. Journal of Higher education today, 88-90.

Hutorskoy, A. V. (2003). Key competences, Technology design. Journal of Education, 5, 61.

Ibragimov, G. I. (2011). Innovative learning technologies in the conditions of implementation of the competency approach. Journal of Innovations in Education, 4, 4.

Isaev, J. F. (2008). The development of professional pedagogical culture under conditions of continuous education (p. 213). Collective monograph Belgorod.Oskol.SOF BSU.

Ivanenko, N. A., Mustafina, G. M., Sagitova, V. R., Akhmetzyanov, I. G., Khazratova, F. V., Salakhova, I. T., \& Mokeyeva, E. V. (2015). Basic components of developing teachers' research competence as a condition to 
improve their competitiveness. Review of European Studies, 7(4), 221-227. http://dx.doi.org/10.5539/res.v7n4p221

Kalimullin, A. M. (2014). Improvement of teachers' qualification at Kazan federal university. World Applied Sciences Journal, 30(4), 447-450.

Levina, E. Y. (2012). Control of education on the basis of quality management. Journal of Fundamental research, 11, 571 .

Levina, E. Y., Akhmetov, L. G., Latipova, L. N., Mirzagitova, A. L., Mirzanagimova, F. I., Latipov, Z. A., \& Masalimova, A. R. (2015). Diagnostics of Educational Activity Quality on the Basis of Qualitative Methods. Asian Social Science, 11(4), 246-251.

Meshcheriakova, E. V. (2013). Features of formation of translation competence as part of training. Journal of Modern problems of science and education, 3, 75.

Mukhametzyanova, G. V. (2010). New Paradigms of Education in training competent professionals. Bulletin of the Moscow State Regional University, Psychological Science, 2, 127.

Novikov, A. M. (2006). Introduction to the methodology of game activity (p. 48). Publisher "Egves".

Potashnik, M. M. (2002). Quality of Education: Problems and Management Technologies, Questions and Answers (1st ed., p. 352). Moscow Pedagogical Society of Russia.

Prokofieva, E. N. (2012). Integrative play in the formation of professional competencies in undergraduate Profile "Protection in emergency situations". Kazan pedagogical journal, 4, 55.

Selezneva, N. A. (2002). Quality of higher education as an object of systematic research (p. 95). Moscow Research Center of the quality of training.

Shaidullina, A. R., Morov, A. V., Morova, N. S., Petrova, T. N., Kirillova, O. V., Kirillova, T. V., \& Riazantzeva, I. M. (2015). The Features of Social Partnership as a Mechanism for the Integration of Education and Production. Review of European Studies, 7(3), 292-297. http://dx.doi.org/10.5539/res.v7n3p292

Sharshov, I. A., (2004). Space professional creative self-development of educational process in high school. Ped, education and science, 5, 72.

Telegina, N. V., Galimova, E. G., \& Masalimova, A. R. (2015). The Structure and Content of the Model of Pedagogical Conditions Binary Approach to Optimization of Control and Diagnostic Functions in Teaching "General pedagogy" to Students. Asian Social Science, 11(1), 364-368.

Zaripova, I. M., Shaidullina, A. R., Upshinskaya, A. Y., Sayfutdinova, G. B., \& Drovnikov, A. S. (2014). Modeling of Petroleum Engineers Design-Technological Competence Forming in Physical-Mathematical Disciplines Studying Process. American Journal of Applied Sciences, 11(7), 1049-1053. http://dx.doi.org/10.3844/ajassp.2014.1049.1053

Zeer, E. F., Pavlova, A. M., \& Symanyuk, E. E. (2005). The modernization of vocational education: Competence approach (p. 216). Moscow Publisher MPSI.

Zimnya, I. A. (2006). Competence approach. What is its place in the modern approaches to education? Journal of Higher education today, 8, 29.

\section{Copyrights}

Copyright for this article is retained by the author(s), with first publication rights granted to the journal. This is an open-access article distributed under the terms and conditions of the Creative Commons Attribution license (http://creativecommons.org/licenses/by/3.0/). 